\title{
Professional Values, Social Capital and the Employment Flow of New-Generation of Migrant Workers
}

\author{
Jianyun Cao \\ South China University of Technology \\ Guangzhou, Guangdong, China \\ jycao@scut.edu.cn
}

\author{
Zhuangchao Ma \\ South China University of Technology \\ Guangzhou, Guangdong, China
}

\begin{abstract}
High-quality employment is the key for the newgeneration of migrant workers to live in cities and finally become citizens. Based on the survey in the Pearl River Delta, the paper analyzes the effect of professional values and social capital on the employment flow of migrant workers using binary Logistic model. Results show that self-development-oriented professional values and social capital can significantly promote stability in employment, changing jobs frequently is highly related to professional values and the amount of social capital. As a result, the new generation of peasant workers should form selfdevelopment-oriented professional values and broaden the way to accumulate social capital.
\end{abstract}

Keywords-New generation of migrant workers; Social capital; Employment flow; Professional values

\section{INTRODUCTION}

At present, the number of new generation of migrant workers has reached 125 million, accounting for $46.6 \%$ of the total migrant workers [1]. Compared with the old generation, their willingness to settle in cities is stronger. Therefore, relatively stable employment is undoubtedly the key to establishing a foothold in the city and eventually citizenship. Existing studies (Knight J, 2004; Lai Yulin, 2009, etc.) show that migrant workers have frequent employment flows [2-3]. Our survey of the Pearl River Delta in July and September 2016 also showed that $39.8 \%$ of the new generation of migrant workers job-hop within one year, and $32.3 \%$ of them quit in 12 years while less than $30 \%$ jump ship after two years. But $60 \%$ of the older generation changed their jobs after 2 years, and only $20 \%$ quitted within 1 year. Compared with the old generation, the employment flow of the new generation of migrant workers is more frequent and more unstable.

The free flow of labor resources can improve the efficiency of resource allocation, promote economic restructuring, improve the quality of laborers, and thus promote economic development. However, it can also easily lead to moral hazard problems, inhibit the investment of human capital, and thus is harmful to technological innovation and economic efficiency improvement. At the same time, income instability caused by unstable employment will, to some extent, curb consumer demand and spending levels. Li Qiang (1999), Bai Nansheng (2008), Zhu Zhisheng (2014) and other researchers found that the employment level of migrant workers is relatively low, most of the employment flow still belongs to the horizontal movement within the informal sector, and frequent "jobhopping", which is seen as a kind of "defect", did not result in changes in position and rise in status. [4] This article believes that the cost of living in a city is higher than that in a rural area. Therefore, in urban life, it is necessary to have relatively stable income as a guarantee. However, frequent and low-level employment flows are obviously not conducive to a stable increase in income and career development, because it is difficult to master and use a professional skill within a short period of time (eg, within 1 year). Currently, most of the labor contracts in companies are signed one year. There are two cases of changing jobs within one year. The first is "jobhopping" during the probation period. Since the labors are still at the stage of familiarization and understanding of the new work, therefore, both the work efficiency and the wages are low. This kind of employment flow will make the income and life of the employed unprotected. The second is the employer's breach of contract after the signing of the labor contract.

If the breach of contract is prevalent, it would be difficult to recover the cost of human capital investment. On the one hand, enterprises will reduce human capital investment for migrant workers, and on the other hand, they will reduce the wages and benefits of migrant workers. This will make it trapped in a vicious circle of "low wages and benefits - jobhopping - lower wages and benefits." Therefore, too frequent "job-hopping" is not conducive to the citizenship of the new generation of migrant workers

What is the reason for the new generation of migrant workers frequently "jobs-hopping"? Yan Shanping (2006), Fu Ping (2009), Yan Xinmin (2012), and Zhang Jianwu (2012) analyzed the effects of individual characteristics such as age, gender, marriage, and education level on the employment flow of migrant workers; Cai He (2009) explained the employment mobility of migrant workers from the perspective of maximizing corporate profits; [5] Xu Jianling (2007), Cui Chuanyi (2008), Zhang Chunni (2011) illuminated this from the perspective of policy systems; Bian Yanjie (1997, 2001) studied the relationship between employment and social capital, and analyzed the mechanism of social capital's impact on employment. [6-7] And based on the above research, Li Peilin 
(2000), Cai Fang (2001), and Zhang Zhiyong (2007) studied the relationship between employment behavior and social capital[8]. They point out the universe impact of social capital on the employment of migrant workers and affirms the positive role of social capital in promoting the employment of migrant workers. It is an indisputable fact that the employment mobility behavior is influenced by social capital. Does the social capital reduce or increase the employment mobility? There is no relevant empirical research conclusion. In addition, according to the study of the values and management behaviors of 72 managers from different industries by England G W\&Keaveny T J (1969), individual behaviors are closely related to their values. What is the relationship between the migrant workers' professional values and their frequent employment flow? Existing research does not give an answer. The new generation of migrant workers is in the formation and maturity of their values. Therefore, the study of the relationship between values and employment mobility will provide a theoretical basis for guiding the new generation of migrant workers to establish correct professional values and achieve high-quality employment.

In view of this, based on the studies of the status quo of the new generation of migrant workers' professional values and social capital, this paper adopts the binary Logistic model to analyze its internal connection with migrant workers' frequent "job-hopping".

\section{DATA SOURCES AND DESCRIPTION}

\section{A. Data sources}

The data comes from our team's random sample survey in the streets of the Pearl River Delta, the earliest and largest source of migrant workers, from July to September 2016. For comparison, two generations of migrant workers were surveyed. A total of 850 questionnaires were distributed and 814 valid questionnaires were retrieved. Of the effective samples, 694 were new generation migrant workers, accounting for $85.3 \%$, of which 386 were male and 436 were unmarried. The old generation of migrant workers was 120 , accounting for $14.7 \%$, of which 83 were male and 8 were unmarried.

\section{B. The current status of the new generation of migrant workers' professional values and social capital}

Due to the lack of a unified measurement standard, this study adopts two indicators, "factors most valued when choosing a job" and "work plan", to reflect the migrant workers' professional values. Table 1 shows that compared with the old generations of migrant workers, the new generation pay more attention to the income factor when choosing a job, but at the same time, the awareness of selfdevelopment and entrepreneurship are also obviously enhanced. The new generation and old generation of migrant workers who chose "highest value and stability" accounted for $53.17 \%$ and $46.67 \%$ respectively, indicating that the new generation pay more attention to the pursuit of material interests but the value orientation has changed significantly. At the same time, self-development awareness of the new generation has increased: $10.81 \%$ of the people most valued the possibility of self-development when choosing a job. This percentage was 5.64 percentage points higher than that of the older generation of migrant workers. As $62.8 \%$ of the new generation of migrant workers in the survey sample are still unmarried, the education of their children is not an imminent problem. Therefore, they have few considerations when choosing a career. The vast majority of new generation of migrant workers put forward higher requirements for their future work: $43.5 \%$ and $14.7 \%$ of them chose "learning technology to increase income" and "move forward to management" respectively. In addition, there are $18.3 \%$ of them choosing "starting my own business in the future", which is $3.3 \%$ higher than the old generation of migrant workers

Job seeking method can only reflect, to a certain extent, the size of social capital, but the social capital owned by migrant workers is also closely related to their non-agricultural employment time, the ownership, the nature of the job, and so on. Therefore, the four factors mentioned above are taken into consideration to reflect the social capital status of migrant workers. Table 1 shows that $67.6 \%$ of the new generation of migrant workers mainly rely on relatives, friends, and school recommendation in their job search, indicating that social networks play an important role in the migrant workers' jobhunting process. However, the dual segmentation of the labor market and the imperfect public employment service system can only enable most migrant workers to achieve informal employment in the secondary labor market, so $70.8 \%$ of new generation migrant workers are concentrated in private enterprises, among which $52.2 \%$ are ordinary workers. By assigning four indicators such as the job seeking method, the non-agricultural employment time, the nature of unit ownership, and the nature of the job, the social capital value is them obtained. The result shows that the average social capital level of the sample is 9.3, of which the new generation and old generation of migrant workers are 8.6 and 13.37 respectively. There are two reasons why the new generation of migrant workers have less social capital. On the one hand, their working time in cities is relatively short. On the other hand, the resources they have in their work units or in their positions are relatively small, which to a certain extent limits the accumulation of social capital. 
TABLE I.

SAMPLE DATA DESCRITION

\begin{tabular}{|c|c|c|c|c|c|c|c|}
\hline Variable & Category & $\begin{array}{l}\text { Proportion } \\
1(\%)\end{array}$ & $\begin{array}{l}\text { Proportion } \\
2(\%)\end{array}$ & Variable & Category & $\begin{array}{l}\text { Proportion } \\
1(\%)\end{array}$ & $\begin{array}{l}\text { Proportion } \\
2(\%)\end{array}$ \\
\hline \multirow{4}{*}{$\begin{array}{c}\text { The most } \\
\text { important factor } \\
\text { when choosing } \\
\text { a job }\end{array}$} & High income and stability & 53.2 & 46.7 & \multirow{3}{*}{ Work plan } & $\begin{array}{l}\text { Learn technology to increase } \\
\text { revenue }\end{array}$ & 43.5 & 31.7 \\
\hline & $\begin{array}{c}\text { self-improvement and } \\
\text { development }\end{array}$ & 10.8 & 5.2 & & Move toward management & 14.7 & 20.8 \\
\hline & $\begin{array}{c}\text { Good work environment, } \\
\text { easy }\end{array}$ & 28.0 & 29.2 & & Self-employed & 18.3 & 15.0 \\
\hline & $\begin{array}{c}\text { Low entry barriers or } \\
\text { convenient for children to } \\
\text { attend school }\end{array}$ & 8.1 & 19.0 & & Keep doing the current job & 23.5 & 32.5 \\
\hline \multirow{3}{*}{$\begin{array}{l}\text { Non- } \\
\text { agricultural } \\
\text { employment } \\
\text { time }\end{array}$} & Within 3 years & 33.6 & 3.3 & \multirow{4}{*}{ Unit ownership } & Individual private enterprise & 70.8 & 60.8 \\
\hline & $3-5$ years & 45.4 & 8.3 & & foreign-funded enterprises & 12.4 & 15.0 \\
\hline & More than 5 years & 21 & 88.4 & & $\begin{array}{c}\text { State-owned collective } \\
\text { enterprises }\end{array}$ & 13.4 & 15.0 \\
\hline \multirow{3}{*}{$\begin{array}{l}\text { Nature of unit } \\
\text { ownership }\end{array}$} & General workers & 52.2 & 30.0 & & Institutions & 3.5 & 9.2 \\
\hline & Technicians & 22.3 & 32.5 & \multirow{2}{*}{$\begin{array}{l}\text { job seeking } \\
\text { method }\end{array}$} & $\begin{array}{c}\text { introduced by relatives and } \\
\text { friends } \\
\end{array}$ & 67.6 & 76.1 \\
\hline & Grassroots managers & 25.5 & 37.5 & & by newspapers, networks, etc. & 32.4 & 23.9 \\
\hline
\end{tabular}

a. Note: The proportion 1 refers to the proportion of the new generation of migrant workers, the proportion 2 refers to the proportion of the old generation of migrant workers.

\section{Models and indicators}

Does the professional value of material interest and low level of social capital accumulation lead to frequent "jobhopping" in the new generation of migrant workers? Based on the framework of internal and external influence paradigm proposed by Farley OW et al [9]., this article divides factors affecting employment flow into internal factors and external factors. Among them, internal factors refer to factors such as physical, psychological and individual social aspects at the micro level; external factors include Meso-level enterprises, families and other factors, as well as macro-level cultural, institutional and other factors. We use binary Logistic model to study the determinants of the new generation of migrant workers employment flow.

The binary Logistic model is:

$$
P\left(y=\left.1\right|_{x_{1}}, x_{2} \cdots x_{n}\right)=F\left(\alpha+\sum_{i=1}^{n} \beta_{i} x_{i}\right)
$$

Among them, y refers to the time interval of employment flow. For example, $y=1$ indicates that the job was changed more than one year. $\mathrm{x} 1, \mathrm{x} 2 \ldots \mathrm{xn}$ are variables that affect the employment mobility. Among them, there are variables such as gender, age, marriage, education level and professional value at the micro level; at the meso-level, there are social capital and variables reflecting the monthly average wages, average working hours, whether to provide job training, whether to pay insurance premiums for employees, whether to sign labor contracts with employees, etc. At the macro level, variables include rights protection and satisfaction with urban life.

\section{EMPIRICAL RESULT}

The estimation results (Table 2) indicate:

Self-developing-oriented professional values can significantly reduce the frequency of migrant workers' jobhopping and increase employment stability. The employment flow rate of migrant workers who value self-development is significantly lower than that of migrant workers who value the working environment and low barriers to entry. Because people who value self-development generally consider less of their immediate interests, they mainly choose employment or "jobhop" from the perspective of long-term development. They are less likely to "job-hop" due to short-term benefits, therefore the frequency of employment flows can be effectively reduced. In addition, because frequent employment flows are not conducive to income growth, migrant workers who pay attention to income growth have lower employment mobility than migrant workers who value the working environment and low barriers to entry, but the difference is not significant.

The social capital of the new generation of migrant workers is positively related to their employment stability. During different periods of social economic system, social capital, especially the strong relationship formed by friends and relatives, plays an important role in job seekers' career acquisition, employment flow, and status promotion, and this role is continuously strengthened (Wang Chunguang, 2000) [9] Under the condition of the imperfect economic system and the asymmetric information in the labor market, social capital can play the role of information bridge, promote the dissemination of labor employment information and shorten the time of job seeking (Bian Yanjie, 2001). Therefore, higher level of social capital can provide job seekers with more choice opportunities, so job seekers can find suitable jobs more easily, thereby effectively reducing the blind flow of employment. 
The educational level and age of the new generation of migrant workers are significantly negatively related to the frequency of employment mobility. This result about the relationship between education level and employment mobility is contrary to those of Knigh J \& Yueh L (2004) and Wu Yongqiu (2007) [10], which may be related to the characteristics of migrant worker groups. The survey shows that $65 \%$ of the new generation of migrant workers have high school education or higher, which is 11.9 percentage points higher than that of the older generation. However, their education level is still lower than that of urban employees. Within this group, those with a higher level of education are easily valued by enterprises and receive higher incomes and a better working environment than other migrant workers. Their opportunity cost of employment flow is high, so their employment is relatively stable.

The influence of corporate environmental factors on the employment mobility of migrant workers has exceeded the influence of institutional factors and social capital. This result is consistent with the findings of Hackes B L \& Hamouz F L (1995) and Yao Jun (2011). From the perspective of opportunity cost, the better the wages and benefits of enterprises, the higher the opportunity cost of employment flows [11-12]. Therefore, the employment stability of migrant workers is positively related to their wages and benefits. The increase in wages, the payment of insurance premiums for migrant workers, the provision of job or skill training, and the signing of labor contracts with migrant workers can all reduce employment flows to a certain extent. Extending the average daily working hours will significantly increase the mobility of employment. However, at present, the income level of the new generation of migrant workers is relatively low, with monthly average wages lower than 1,800 yuan and $1,800-3,000$ yuan accounting for $24.1 \%$ and $54 \%$, respectively, while $50 \%$ of the old generation are above 3,000 yuan. In addition, the basic rights and interests of the new generation of migrant workers are still lack of protection, and labor contract signing rate and social insurance participation rate is not high (only $53.5 \%$ of new generation of migrant workers and enterprises signed a labor contract), while $31.8 \%$ of people did not participate in any social insurance.

\section{TABLE II. INFLUENCING FACTORS OF EMPLOYMENT FLOW BEHAVIOR OR NEW GENERATION}

\begin{tabular}{|c|c|c|c|}
\hline & & $\begin{array}{l}\text { Regression coefficients } \\
\text { B }\end{array}$ & Marginal Effect Exp（B） \\
\hline \multicolumn{2}{|c|}{ Gender (reference group: female) } & 0.248 & 1.281 \\
\hline \multicolumn{2}{|r|}{ Age } & $0.421 * *$ & 1.523 \\
\hline \multicolumn{2}{|c|}{ Education level } & $0.072 *$ & 1.075 \\
\hline \multicolumn{2}{|c|}{ Marriage (reference group: married) } & 0.086 & 1.09 \\
\hline \multicolumn{4}{|c|}{ Career selection criteria (reference group: other types) } \\
\hline \multicolumn{2}{|c|}{ Self-improvement and development } & $0.433 * *$ & 1.542 \\
\hline \multicolumn{2}{|c|}{ Revenue growth } & 0.057 & 1.059 \\
\hline \multicolumn{4}{|c|}{ Work plan (reference group: Continue to do current work) } \\
\hline \multicolumn{2}{|c|}{ Self-employed } & 0.032 & 1.032 \\
\hline \multicolumn{2}{|c|}{ Learning technology, moving toward management } & -0.209 & 0.811 \\
\hline \multicolumn{2}{|c|}{ Average monthly salary } & $0.516^{* * *}$ & 1.675 \\
\hline \multicolumn{2}{|c|}{ Average daily working hours } & -0.068 & 0.934 \\
\hline \multicolumn{2}{|c|}{ Job or skills training (Referral group: No) } & 0.285 & 1.33 \\
\hline \multicolumn{2}{|c|}{ Pay insurance premiums for employees (reference group: No) } & $0.584 * * *$ & 1.793 \\
\hline \multicolumn{2}{|c|}{ Sign labor contracts with employees (reference group: No) } & 0.187 & 1.206 \\
\hline \multicolumn{2}{|c|}{ Social capital } & $0.093 *$ & 1.097 \\
\hline \multicolumn{2}{|c|}{ Rights protection (Reference group: silent endurance or violent resolution) } & $-0.726 * * *$ & 0.484 \\
\hline \multicolumn{2}{|c|}{ Satisfaction with city life (Reference group: No) } & $0.485 * * *$ & 1.625 \\
\hline \multicolumn{2}{|c|}{ Constant } & $-2.531 * * *$ & 0.08 \\
\hline Number of samples & 694 & Chi-square value & 116.977 \\
\hline Nagelkerke $\mathrm{R}^{2}$ & 0.222 & Cox\&Snell $\mathrm{R}^{2}$ & 0.155 \\
\hline Forecast accuracy $(\%)$ & 76.7 & & \\
\hline
\end{tabular}


A sound legal system can reduce barriers to employment mobility and promote the free flow of labor, while inclusive urban culture can significantly reduce the blind flow of migrant workers' employment. The policy system, especially the legal system design, is basically about institutional design of property rights. The size of the laborers' decision-making power depends to a great extent on different property rights or human rights systems. With the continuous reform of the policy system and the gradual improvement of the legal system, the migrant workers' employment and mobility barriers have been reduced, legal awareness has been continuously enhanced, and their internal development aspirations and preferences can be fully displayed when choosing a career. When their rights and interests are infringed, they can handle it by legal means or by leaders and friends. This can promote the free flow of labor. Secondly, the more satisfied the migrant workers are with urban life, the higher their employment stability is. An inclusive urban culture can prevent migrant workers from being discriminated against, increase their willingness to take root in cities, and contribute to the stability of employment.

\section{CONCLUSIONS AND SUGGESTIONS}

High-quality employment is the key for the new generation of migrant workers to live in cities and ultimately become citizens. However, the employment instability and too frequent employment flows of the new generation of migrant workers are not conducive to the realization of citizenization. In addition to being influenced by factors such as age, education level, wages and benefits, and cultural and institutional factors, their employment mobility behavior is also affected by professional values and social capital. The more attention paid to self-development and the more social capital, the lower the employment migration frequency of migrant workers would be. Therefore, to reduce blind employment flows, they must focus on cultivating selfdevelopment professional values. The new generation of migrant workers is in the formation and maturity of their values. Institutional development and education should provide soil for the development of migrant workers' selfdevelopment professional values. In addition, it is necessary to broaden the way for the accumulation of social capital for the new generation of migrant workers. The traditional social capital relies mainly on the "three edges" (blood, kinship, and geopolitical) accumulation. With the advancement of science and technology and the improvement of the new generation of migrant workers' cultural level, the accumulation of social capital should base on industry and network. In addition to the need for migrant workers to increase their awareness of social capital, expand their social range, make full use of modern and advanced information networks, and exert their subjective initiative, the need for government promotion is more pressing The government should attach great importance to the accumulation of social capital for migrant workers, and strengthen infrastructure construction such as rural networks and communications, encourage and guide the growth and expansion of non-governmental organizations serving migrant workers, and build social network platforms for migrant workers.

\section{ACKNOWLEDGMENT}

This research was financially supported by the following projects: (1) General Project of Humanities and Social Sciences Research of the Ministry of Education. "Research on Innovation Performance and Innovation Path of PatentIntensive Industries" (Granted No. 17YJC790003); (2) Soft Science Project of Guangdong Science and Technology Department in 2015." Cultivating and Institutional Innovation of Guangdong's Strategic Emerging Industries' Core Competence" (Granted No. 2015A070704006); (3) Philosophy and social science project of Guangdong province in 2014." Research on Cooperative Aggregation of Manufacturing and Producer Services in Guangdong (Granted No. GD14YLJ01). (4) Philosophy and social science project of Guangzhou in 2015." Research on the Development Mechanism and Path for the Integration of Modern Service Industry and Manufacturing Industry in Guangzhou) (Granted No. 15G06).

\section{REFERENCES}

[1] National Bureau of Statistics. National Monitoring Report on Migrant Workers in 2013 [DB/OL]. http://www.stats.gov.cn/tjsj/zxfb/201405/t20140512_551585.html, 2014-05-12

[2] Knight J, Yueh L. Job mobility of residents and migrants in urban China[J]. Journal of Comparative Economics, 2004, 32(3).

[3] Bai Nansheng, Li Jing. Research on Employment Liquidity of Migrant Workers[J]. Management World, 2008, (7).

[4] Li Qiang. Occupational mobility of rural migrant workers in Chinese cities[J]. Sociological Studies, 1999, (3). 